\title{
Genetic evaluation of juvenile xanthogranuloma: genomic abnormalities are uncommon in solitary lesions, advanced cases may show more complexity
}

\author{
Christian N Paxton ${ }^{1}$, Dennis P O’Malley ${ }^{2}$, Andrew M Bellizzi ${ }^{3}$, Deema Alkapalan ${ }^{3}$, \\ Yuri Fedoriw ${ }^{4}$, Jason L Hornick ${ }^{5}$, Sherrie L Perkins ${ }^{1,6}$, Sarah T South ${ }^{1,6,7}$ and \\ Erica F Andersen ${ }^{1,6}$
}

${ }^{1}$ ARUP Institute for Clinical and Experimental Pathology, Salt Lake City, UT, USA; ${ }^{2}$ Department of Pathology, Clarient Pathology Services, Aliso Viejo, CA, USA; ${ }^{3}$ Department of Pathology, University of Iowa Hospitals and Clinics, Iowa City, IA, USA; ${ }^{4}$ Department of Pathology and Laboratory Medicine, University of North Carolina School of Medicine, Chapel Hill, NC, USA; ${ }^{5}$ Department of Pathology, Brigham and Women's Hospital, Boston, MA, USA and ${ }^{6}$ Department of Pathology, University of Utah School of Medicine, Salt Lake City, UT, USA

\begin{abstract}
Juvenile xanthogranuloma is a rare histiocytic proliferation primarily affecting infants and young children, characterized by aberrant infiltration of histiocyte-derived cells in the skin, soft tissues and more rarely, visceral organs. Juvenile xanthogranuloma is generally considered to be a benign disorder; most lesions are solitary cutaneous nodules that resolve spontaneously without treatment. However, cases with extracutaneous involvement, multiple lesions, and/or systemic disease often require aggressive therapy. Though molecular studies have provided evidence of clonality in juvenile xanthogranuloma, in support of a neoplastic process, little is known about the genetic profile of juvenile xanthogranuloma. We used molecular inversion probe array technology to evaluate the genomic characteristics (copy number alterations or copy neutral-loss of heterozygosity) of 21 archived cases of juvenile xanthogranuloma (19 solitary, 1 diffuse cutaneous, 1 systemic). Four cases $(19 \%)$ showed acquired, clonal alterations. Two lesions from a case of diffuse cutaneous juvenile xanthogranuloma showed distinct profiles: JXG-1a contained trisomy 5 and 17 and JXG-1b contained loss of heterozygosity in 5q. The systemic juvenile xanthogranuloma (JXG-2) showed multiple genomic alterations. Only two of 19 solitary juvenile xanthogranulomas showed abnormal genomic profiles: JXG-3 showed gains on 1q and $11 q$ and JXG-4 showed a $7.2 \mathrm{Mb}$ loss in 3p. No recurrent abnormalities were observed among these cases. The presence of non-recurrent copy number alterations in a subset of samples implies that copy number changes are unlikely driving pathogenesis in juvenile xanthogranuloma, but may be acquired during disease progression. The presence of genomic abnormalities in more advanced cases (ie, systemic and diffuse cutaneous juvenile xanthogranuloma) supports this notion, particularly as the advanced cases of juvenile xanthogranuloma presented more genomic complexity.
\end{abstract}

Modern Pathology (2017) 30, 1234-1240; doi:10.1038/modpathol.2017.50; published online 28 July 2017

Juvenile xanthogranuloma is an uncommon proliferation of histiocytic lineage primarily affecting infants and young children, with occasional cases

Correspondence: Dr CN Paxton, PhD, Research and Development ARUP Laboratories, 500 Chipeta Way, Salt Lake City, UT 84108, USA.

E-mail: christian.n.paxton@aruplab.com

${ }^{7}$ Current address: AncestryDNA, Lehi, Utah

Received 17 November 2016; revised 10 April 2017; accepted 19

April 2017; published online 28 July 2017 seen in adults. ${ }^{1}$ Characterized by aberrant infiltration of histiocyte-derived cells in the skin, juvenile xanthogranuloma is generally considered to be a benign disorder. ${ }^{2-4}$ Although the incidence of juvenile xanthogranuloma has never been truly evaluated in the general population, a retrospective study of the Kiel Pediatric Tumor Registry reported 129 juvenile xanthogranuloma cases diagnosed out of 24600 registered patients (incidence rate of $0.52 \%$ ) over a 36 -year span. ${ }^{3}$ 
Juvenile xanthogranuloma typically presents as a solitary cutaneous nodule that develops on the head, neck or trunk. Occasionally extracutaneous presentation of nodules occurs within the eye, soft tissues or visceral organs. ${ }^{3-5}$ Systemic juvenile xanthogranuloma, which involves the visceral organs, is rare, occurring in $<5 \%$ of cases. ${ }^{2,3}$ Solitary cutaneous nodules often resolve spontaneously without treatment or are treated by simple tumor excision, however, disseminated cases that present as multiple cutaneous lesions or involve the visceral organs in systemic disease may be serious, requiring aggressive therapy. ${ }^{3,4}$

Histiocytic lesions are diagnosed and characterized primarily through histopathology and immunohistochemistry. Little is known about the genetics of juvenile xanthogranuloma. In addition to a typically early age of onset, observations including a reported case of juvenile xanthogranuloma in monozygotic twins, ${ }^{6}$ as well as identification of $N F 1$ and NF2 germline mutations in a subset of patients, ${ }^{7-9}$ indicate that there may be a constitutional predisposition to develop juvenile xanthogranuloma, at least in some patients. NF1 and NF2 encode proteins that function within the mitogen activated protein kinase (MAPK) pathway, a pathway that has a key role in regulating the cell cycle, cell growth and differentiation, and cell senescence. ${ }^{10}$ Activating mutations in MAPK genes are found in the germline in several developmental and cancer predisposition syndromes as well as acquired somatically in a wide range of cancers. Juvenile xanthogranuloma patients with $N F 1$ or NF2 germline mutations are reported to have an increased risk of juvenile myelomonocytic leukemia, a myeloproliferative neoplasm of childhood associated with both germline and somatic MAPK pathway mutations. ${ }^{9,11,12}$ These observations suggest a potential role for MAPK signaling in juvenile xanthogranuloma.

Studies by whole-exome sequencing have provided additional support for a role for MAPK signaling in juvenile xanthogranuloma. Diamond et al. ${ }^{13}$ recently identified mutations involving MAPK pathway genes NRAS, KRAS, ARAF, and MAP2K1 in 7 out of 12 systemic juvenile xanthogranuloma cases. Another study by Chakraborty and colleagues reported two cases of mixed Langerhans cell histiocytosis/juvenile xanthogranuloma phenotypes that contained the BRAFV600E mutation. ${ }^{6}$ Approximately $50 \%$ of Langerhans cell histiocytosis and Erdheim-Chester disease-additional histiocytic disorders-are reported to contain the BRAFV600E mutation. ${ }^{14-16}$ Although $B R A F$ mutations have not been observed in cases with a purely juvenile xanthogranuloma phenotype to date, ${ }^{8}$ Diamond et al. ${ }^{13}$ did identify an RNF11-BRAF fusion in one of their systemic juvenile xanthogranuloma cases. This finding may indicate that, at least in some incidences of juvenile xanthogranuloma, (1) $B R A F$ involvement cannot be ruled out and (2) translocations may also be involved in juvenile xanthogranuloma. Chakraborty et al. ${ }^{7}$ also identified a PIK3CD mutation in serial biopsies of a single patient, suggesting that the PI3K pathway may also be involved in juvenile xanthogranuloma progression. ${ }^{8}$

Although emerging sequencing-based data suggest activating mutations may have an important role in juvenile xanthogranuloma pathogenesis, these findings have not been universal. Little is known about the potential contribution of copy number alterations, which are common across many cancers, in juvenile xanthogranuloma. To date, only normal karyotypes have been observed in cases with concurrent cytogenetic studies. ${ }^{17-21}$ Cytogenomic microarray analysis is a widely used genomic profiling technology, providing much higher resolution for detection of copy number alterations compared to traditional cytogenetic studies, as well as for detection of loss-of-heterozygosity, a common genomic alteration in cancer. Here, we evaluated the genomic profile of juvenile xanthogranuloma lesions by molecular inversion probe array, which is optimized for use on archived samples. ${ }^{22-25}$

\section{Materials and methods}

\section{Patient Samples}

Lesions from a total of 21 archived juvenile xanthogranuloma cases were obtained from several institutions. Histological review of H\&E-stained slides was performed by the contributing pathologists and the diagnosis of juvenile xanthogranuloma was confirmed by experienced pathologists $(\mathrm{AB}, \mathrm{YK}, \mathrm{JH}$, DO, LW) based on standard WHO 2008 classification criteria. $^{26}$ Representative H\&E images of selected cases from this cohort are provided (Figure 1). Tumor content (40-90\%) was estimated during pathologist review. Patient samples were deidentified and used in accordance with University of Utah Institutional Review Board regulations.

\section{DNA Isolation, Processing, and Array Hybridization}

Genomic DNA was extracted using the QIAamp DNA FFPE Tissue Kit (QIAGEN, Valencia, CA, USA) and quantitated by Qubit PicoGreen (Life Technologies, Carlsbad, CA, USA). Approximately 80 ng genomic DNA was utilized for molecular inversion probe array analysis. Genomic analysis was performed using the OncoScan FFPE Assay kit (Affymetrix, Santa Clara, CA, USA). All samples were processed using a modified OncoScan protocol. ${ }^{27}$ In brief, genomic DNA was hybridized to a series of molecular inversion probes, which target $\sim 40 \mathrm{bp}$ regions across the genome and anneal to genomic DNA such that each probe forms an inverted loop flanking a single nucleotide polymorphism. Complementary dinucleotides were then incorporated to form a circularized probe, followed by exonuclease treatment, which was used to remove genomic DNA and unused probes. Probes were then re-linearized for 

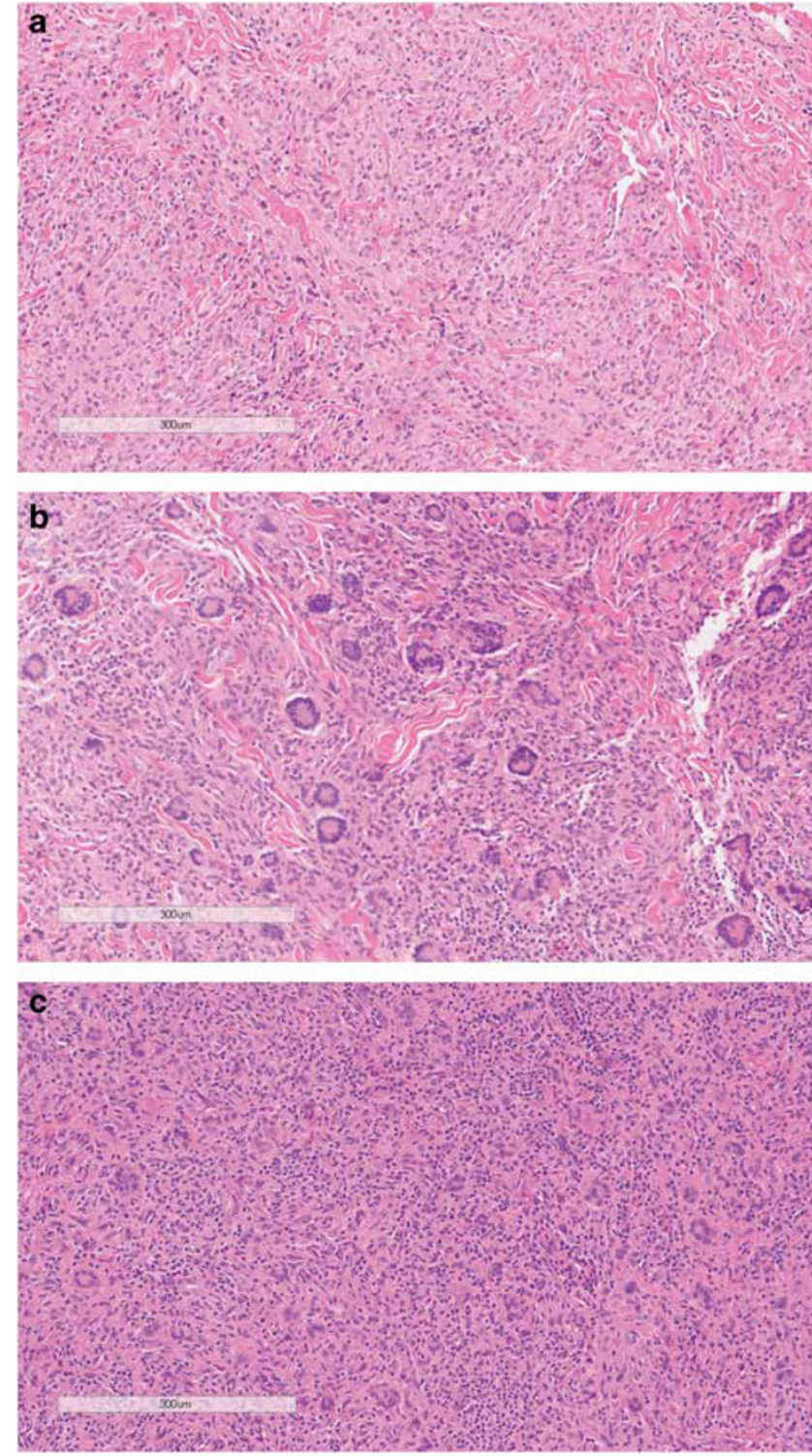

Figure 1 Histopathology of selected juvenile xanthogranuloma lesions with abnormal genomic profiles. (a-c). Hematoxylin and eosin stain $(\times 200)$. Juvenile xanthogranuloma lesions display diffuse fibrohistiocytic proliferations with bland round to oval nuclei, admixed lymphocytes and occasional eosinophils. Touton giant cells (shown in $\mathbf{b}$ and $\mathbf{c}$ ) are also common. (a-b). Two distinct lesions (JXG-1a and JXG-1b, respectively) from a single patient with disseminated juvenile xanthogranuloma. (c). A solitary cutaneous lesion (JXG-3).

amplification. Each probe contained a unique sequence identifier tag (barcode), for hybridization to a high-density microarray.

\section{Data Processing and Analysis}

Data processing was performed using OncoScan Console (Affymetrix). Analysis was performed using Nexus Express Software for OncoScan 3.1 (Biodiscovery, Hawthorne, CA, USA) with reference to human genome assembly GRCh37/hg19. All files were processed using Affymetrix TuScan segmentation algorithm with default parameters. All copy number alterations and loss of heterozygosity calls were manually reviewed.

Level of mosaicism (\% mosaicism) for each call was determined from genotype data (B-allele frequency and/or allele difference values) using calculations as described. ${ }^{28}$ Clonal burden was estimated either from the OS-\% Aberrant Cells algorithm in Nexus or from average $\%$ mosaicism within each case.

\section{Results}

Molecular inversion probe array analysis was performed on 21 cases of juvenile xanthogranuloma (Table 1). The cohort included 14 female and 7 male patients. Ages ranged from 11 months to 60 years, (median age: 3 years). The majority of cases were solitary lesions ( $n=19 ; 90.5 \%)$, including 1 subcutaneous and 18 cutaneous lesions (JXG-3-21). There was a single case of diffuse cutaneous juvenile xanthogranuloma, from which two separate lesions (JXG-1a and 1b) were submitted, and a single case of systemic juvenile xanthogranuloma (JXG-2).

Four cases $(19.0 \%)$ showed copy number alterations and/or loss of heterozygosity (JXG-1-4; Table 1, Figure 2). Clonal burden ranged from 15 to $60 \%$, consistent with an acquired, somatic origin for these alterations. No recurrent genomic alterations were observed across these cases, and of the genes with reported mutations in juvenile xanthogranuloma, only PIK3CD coincided with the altered genomic regions. A general trend of increasing genomic complexity with staging was noted as the abnormalities in the two more advanced stage cases (JXG-1 and 2) involved a larger portion of the genome than the two abnormal solitary lesions (JXG-3-4; Table 1). The remaining 17 cases $(81.0 \%)$ of solitary, cutaneous or subcutaneous lesions showed normal diploid genomes (JXG-5-21; Figure 2e).

\section{Descriptions of Each Abnormal Case Follow}

$J X G$-1. A 1-year-old male presented with extensive cutaneous juvenile xanthogranuloma with ocular involvement. Biopsies were obtained from two separate lesions (JXG-1a from the abdomen and JXG-1b from the right arm; Table 1). Morphologic differences were observed in the two individual lesions with giant Touton cells identified in JXG-1b, but lacking from JXG-1a (Figures 1a and b). Although genomic alterations were identified in both lesions, distinct and relatively large genomic changes occurred in each lesion (Figure 2a). JXG-1a contained trisomies of chromosomes 5 and 17, whereas JXG-1b had a $110 \mathrm{Mb}$ terminal region of homozygosity, consistent with copy neutral-loss of heterozygosity, along the q-arm of chromosome 5. A skin exam 6 years after diagnosis showed deflated lesions on 
Table 1 Characteristics and genomic alterations of juvenile xanthogranuloma cases

\begin{tabular}{|c|c|c|c|c|c|c|c|c|}
\hline$J X G I D$ & Lesion type & Sex & Age & Biopsy site & $C N A / L O H$ & $\begin{array}{l}\text { Clonal } \\
\text { burden }\end{array}$ & $\begin{array}{l}\text { Genomic coordinates } \\
\text { (GRCh37/hg19) }\end{array}$ & $\begin{array}{c}\text { Genome } \\
\text { involvement }\end{array}$ \\
\hline 1 & $\begin{array}{l}\text { Extensive cutaneous } \\
\text { with ocular } \\
\text { involvement }\end{array}$ & Male & $1 y$ & $\begin{array}{l}\text { A: Abdomen } \\
\text { B: Right arm }\end{array}$ & $\begin{array}{l}\text { Lesion A: }+5,+17 \\
\text { Lesion B: LOH } \\
\text { 5q13.2-q35.3 }\end{array}$ & $\begin{array}{l}\text { A: } 50 \% \\
\text { B: } 35 \%\end{array}$ & $\begin{array}{l}\text { A: Trisomy } 5 \text {, } \\
\text { Trisomy } 17 \\
\text { B: Chr5:70,306, } \\
678-180,698,312\end{array}$ & $8.47 \%$ \\
\hline 2 & Systemic & Female & $49 y$ & $\begin{array}{l}\text { Right upper arm/ } \\
\text { Right femoral mass } \\
\text { (lymph node) }\end{array}$ & $\begin{array}{l}\text { LOH 1p36.33-p36.31 } \\
\text { LOH 6p25.3-p21.2 } \\
\text { LOH 9p24.3-p13.3 } \\
\text { LOH 16p13.3-p12.3 } \\
\text { LOH 19p13.3 } \\
\text { Gain 7q21.11-q32.3 } \\
\text { Loss 10q23.1-q25.1 } \\
\text { Loss 19p13.3-p13.2 }\end{array}$ & $15 \%$ & $\begin{array}{l}\text { Chr1:1-19,679,873 } \\
\text { Chr6:1-36,766,292 } \\
\text { Chr9:1-35,482,075 } \\
\text { Chr16:1-17,469,494 } \\
\text { Chr19:1-4,669,675 } \\
\text { Chr7:89,719, } \\
\text { 729-132,706,981 } \\
\text { Chr10:84,918, } \\
\text { 329-109,814,480 } \\
\text { Chr19:4,674, } \\
\text { 113-13,752,280 }\end{array}$ & $6.49 \%$ \\
\hline 3 & Solitary cutaneous & Female & $12 y$ & Right elbow & $\begin{array}{l}\text { Gain 1q21.1-q32.1 } \\
\text { Gains 11q11-q13.4 } \\
\text { 11q23.1-q23.3 } \\
\text { 11q24.1-q25 }\end{array}$ & $40 \%$ & $\begin{array}{l}\text { Chr1:144,009, } \\
053-249,212,878 \\
\text { Chr11:54,795, } \\
357-73,167,739 \\
\text { Chr11:110,777, } \\
257-120,067,082 \\
\text { Chr11:123,471, } \\
031-134,938,847\end{array}$ & $3.26 \%$ \\
\hline 4 & Solitary cutaneous & Female & $9 y$ & Columella & Loss 3p21.31-p21.1 & $25 \%$ & $\begin{array}{l}\text { Chr3:45,170, } \\
095-52,338,852\end{array}$ & $0.23 \%$ \\
\hline 5 & Solitary cutaneous & Female & $3 y$ & Right Lower Eyelid & - & - & N/A & $\mathrm{N} / \mathrm{A}$ \\
\hline 6 & Solitary cutaneous & Female & $3 y$ & Left thigh Mass & - & - & N/A & N/A \\
\hline 7 & Solitary cutaneous & Male & $4 y$ & Right scalp & - & - & $\mathrm{N} / \mathrm{A}$ & $\mathrm{N} / \mathrm{A}$ \\
\hline 8 & Solitary cutaneous & Male & $1 \mathrm{y}$ & Right Abdomen & - & - & N/A & N/A \\
\hline 9 & Solitary cutaneous & Female & $1 \mathrm{y}$ & Right scalp & - & - & $\mathrm{N} / \mathrm{A}$ & N/A \\
\hline 10 & Solitary cutaneous & Female & $20 y$ & Left inner buttock & - & - & $\mathrm{N} / \mathrm{A}$ & $\mathrm{N} / \mathrm{A}$ \\
\hline 11 & Solitary cutaneous & Male & $2 y$ & Right forehead & - & - & $\mathrm{N} / \mathrm{A}$ & $\mathrm{N} / \mathrm{A}$ \\
\hline 12 & Solitary cutaneous & Female & $1 y$ & Posterior scalp & - & - & N/A & N/A \\
\hline 13 & Solitary cutaneous & Female & $1 \mathrm{y}$ & Left mid back & - & - & $\mathrm{N} / \mathrm{A}$ & $\mathrm{N} / \mathrm{A}$ \\
\hline 14 & Solitary cutaneous & Male & $19 y$ & Right chin & - & - & N/A & N/A \\
\hline 15 & Solitary cutaneous & Female & $11 \mathrm{~m}$ & $\begin{array}{l}\text { Right lower } \\
\text { posterior leg }\end{array}$ & - & - & $\mathrm{N} / \mathrm{A}$ & N/A \\
\hline 16 & Solitary cutaneous & Male & $1 \mathrm{y}$ & Left inner thigh & - & - & $\mathrm{N} / \mathrm{A}$ & N/A \\
\hline 17 & Solitary cutaneous & Male & $31 \mathrm{y}$ & Left thigh & - & - & $\mathrm{N} / \mathrm{A}$ & $\mathrm{N} / \mathrm{A}$ \\
\hline 18 & Solitary cutaneous & Female & $2 y$ & Left cheek & - & - & $\mathrm{N} / \mathrm{A}$ & N/A \\
\hline 19 & Solitary cutaneous & Female & $15 y$ & Thigh & - & - & N/A & N/A \\
\hline 20 & Solitary cutaneous & Female & $60 y$ & Right nasal vestibule & - & - & $\mathrm{N} / \mathrm{A}$ & N/A \\
\hline 21 & Solitary cutaneous & Female & $16 y$ & Abdominal wall & - & - & N/A & N/A \\
\hline
\end{tabular}

Abbreviations: CNA: copy number alterations; LOH: loss of heterozygosity.

the nose and depressed scars on the trunk, although a new lesion was present on the left ear. The patient was on a weekly methotrexate treatment with a daily supplement of folate.

JXG-2. A 49-year-old female with systemic juvenile xanthogranuloma. Genomic analysis was performed on a combined tissue sample from this patient that included a biopsied lymph node from upper, right leg and a skin lesion from the right arm (Table 1). Full clinical information of this patient indicating involvement of additional organs or viscera was not available. Eight alterations were identified on seven chromosomes: three involved copy number changes including a $46.8 \mathrm{Mb}$ interstitial gain in $7 \mathrm{q}$, a $24.9 \mathrm{Mb}$ interstitial loss in $10 \mathrm{q}$ and a $9.1 \mathrm{Mb}$ interstitial loss in 19q, and 5 were terminal regions of homozygosity including $19.7 \mathrm{Mb}$ overlapping
PIK3CD on $1 \mathrm{p}, 36.8 \mathrm{Mb}$ on $6 \mathrm{p}, 35.5 \mathrm{Mb}$ on $9 \mathrm{p}$, $17.5 \mathrm{Mb}$ on $16 \mathrm{p}$ and $4.7 \mathrm{Mb}$ on $19 \mathrm{p}$ (Figure 2b). Follow-up information was unavailable.

JXG-3. A 12-year-old female presented with a solitary cutaneous lesion (Figure 1c). Array analysis showed four gains involving chromosomes $1 \mathrm{q}$ and 11q: a $61.9 \mathrm{Mb}$ gain in proximal $1 \mathrm{q}$ and three noncontiguous gains in 11q: $18.4 \mathrm{Mb}$ from $11 \mathrm{q} 11$ to $11 \mathrm{q} 13.4 ; 9.3 \mathrm{Mb}$ from $11 \mathrm{q} 23.1$ to $11 \mathrm{q} 23.3$; and 11.5 Mb from 11q24.2 to 11q25 (Figure 2c). Followup information was not available for this patient.

JXG-4. A 9-year-old female presented with a solitary cutaneous lesion on the nose. Array analysis identified a single $7.2 \mathrm{Mb}$ interstitial deletion from 3p21.31 to 3p21.1 (Figure 2d). The lesion was removed 3 months after diagnosis, and follow-up 

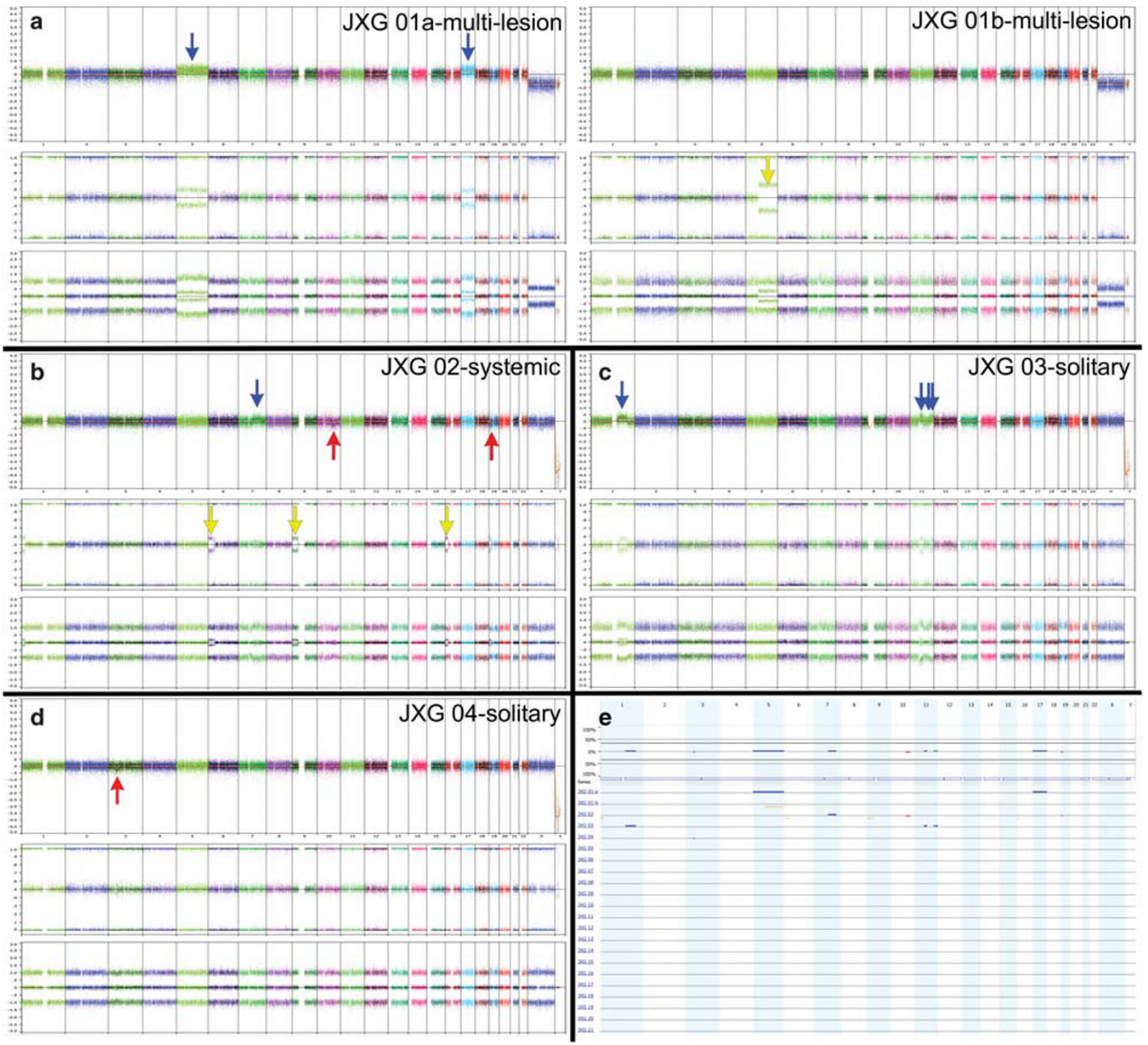

Figure 2 Genomic profiles of 21 juvenile xanthogranuloma cases. Copy number alterations were identified in five specimens from four patients (JXG-1-4). (a) Non-recurrent copy number alterations in two lesions from disseminated juvenile xanthogranuloma. JXG-1a (left) showed trisomy 5 and trisomy 17 (blue arrows). JXG-1b (right) showed copy neutral-loss of heterozygosity in chromosome 5q (yellow arrow). (b) Systemic juvenile xanthogranuloma (JXG-2) with complex genomic profile including copy neutral-loss of heterozygosity in 1p, 6p, 9p, 16p and 19p (yellow arrows), a gain in 7q (blue arrow), and losses in 10q and 19p (red arrows). (c) Solitary cutaneous lesion (JXG-3) with gains in 1q and 11q. (d) Solitary cutaneous lesion (JXG-4) with a loss in 3p. (e) Whole genome view of this cohort. Five lesions (cases 1-4) contained genomic alterations (red = single copy loss, blue = single copy gain, yellow $=\mathrm{LOH}$ ). The remaining 17 cases (all solitary cutaneous juvenile xanthogranuloma) had normal diploid genomes. Chromosomes represented in order (1-22,X,Y) by individual columns.

showed no further evidence of disease over a 6-year period.

\section{Discussion}

The purpose of this study was to further define the genomic landscape of juvenile xanthogranuloma by identifying copy number alterations and loss of heterozygosity in juvenile xanthogranuloma lesions. Genomic analysis of 21 cases of juvenile xanthogranuloma by molecular inversion probe array revealed that the majority of solitary cutaneous juvenile xanthogranuloma lesions are genomically quiet, with no identifiable genomic abnormalities. These findings suggest that copy number alterations and loss of heterozygosity do not primarily contribute to development of these lesions. Though recent sequence-based analyses of juvenile xanthogranuloma have mostly focused on advanced stage juvenile xanthogranuloma, our findings support the generally benign nature of solitary cutaneous 
juvenile xanthogranuloma. The presence of copy number changes in only two solitary cutaneous lesions of this cohort indicates that these types of genomic alterations are uncommon in solitary juvenile xanthogranuloma. Clinical follow-up was available for one of the two solitary lesions with copy number alterations. Tumor excision was performed, and over a 6-year period the patient showed no recurrence or progression of disease, further suggesting that copy number changes do not drive disease development or progression.

Whole-exome sequencing studies have suggested a role for the MAPK and PI3K signaling pathways in juvenile xanthogranuloma development. Specifically, somatic mutations have been identified in KRAS, NRAS, ARAF, and MAP2K $1^{13}$ and PIK3CD. ${ }^{7}$ As copy number alterations and loss of heterozygosity provide mechanisms for unmasking haploinsufficient and recessive-acting loss-of-function alleles, or for duplication of gain-of-function mutations, we investigated whether any of these genes reside within the genomic alterations identified by our analysis. None of the MAPK genes with reported mutations in juvenile xanthogranuloma coincided with our observed genomic alterations, but PIK3CD mapped to the region of chromosome 1 with copy neutral-loss of heterozygosity in JXG-2. Additional gene mutations reported in juvenile xanthogranuloma that are not involved in the MAPK or PI3K pathways ${ }^{7}$ also map outside of these regions. In addition to sequence-level alterations, balanced rearrangements, including translocationssuch as that reported by Diamond et al. ${ }^{13}$-and inversions cannot be detected by molecular inversion probe array. Therefore, additional studies are needed to incorporate genomic alterations with mutation and translocation detection.

Four cases in this cohort showed abnormal genomic profiles, with no recurrent abnormalities. A review of these four cases with genomic changes showed that no histologic differences were observed, but that each of these lesions had typical histology for juvenile xanthogranuloma. In addition, the profiles of two separate lesions from the same patient (JXG-1) were distinct. These findings suggest that these clonal genomic alterations were acquired secondarily, rather than occurring in the initial development of these lesions. Though limited in number, the systemic and disseminated cases showed greater genomic complexity and provide the basis to further study how copy number alterations/loss of heterozygosity correlates with staging in juvenile xanthogranuloma.

It is also important to consider cases of juvenile xanthogranuloma which occur in association with other related disorders, including juvenile myelomonocytic leukemia, Langerhans cell histiocytosis and other BRAF-mutated dendritic and histiocytic neoplasms. These cases may share immunophenotypic features with juvenile xanthogranuloma, but may have an underlying clonal relationship to neoplastic cells. For example, adults with solitary and systemic xanthogranuloma lesions may be a manifestation of Erdheim-Chester disease, and may warrant further evaluation, including testing for gain-of function mutations in $B R A F$, NRAS, KRAS, or $M A P 2 K 1$, which are associated with ErdheimChester disease. Radiologic examination for typical bone features of Erdheim-Chester disease may also be of benefit. Our adult cases (JXG-2 and JXG-20) did not have available clinical or radiographic follow-up for further evaluation. Further studies of juvenile xanthogranuloma, including mutation profiles, relationship of systemic to solitary cutaneous disease and coincidence with other histiocytic/dendritic cell neoplasms is warranted.

\section{Acknowledgments}

We thank Dr Lawrence Weiss for his case contribution to this study. Support for this research was provided by the ARUP Institute for Clinical and Experimental Pathology.

\section{Disclosure/conflict of interest}

The authors declare no conflict of interest.

\section{References}

1 Sandell RF, Carter JM, Folpe AL. Solitary (juvenile) xanthogranuloma: a comprehensive immunohistochemical study emphasizing recently developed markers of histiocytic lineage. Hum Pathol 2015;46:1390-1397.

2 Dehner LP. Juvenile xanthogranulomas in the first two decades of life: a clinicopathologic study of 174 cases with cutaneous and extracutaneous manifestations. Am J Surg Pathol 2003;27:579-593.

3 Janssen D, Harms D. Juvenile xanthogranuloma in childhood and adolescence: a clinicopathologic study of 129 patients from the kiel pediatric tumor registry. Am J Surg Pathol 2005;29:21-28.

4 Stover DG, Alapati S, Regueira O, et al. Treatment of juvenile xanthogranuloma. Pediatr Blood Cancer 2008;51:130-133.

5 Chang MW, Frieden IJ, Good W. The risk intraocular juvenile xanthogranuloma: survey of current practices and assessment of risk. J Am Acad Dermatol 1996;34:445-449.

6 Tan KW, Koh MJ, Tay YK. Juvenile xanthogranuloma in monozygotic twins. Pediatr Dermatol 2010;27:666-667.

7 Chakraborty R, Hampton OA, Shen X, et al. Mutually exclusive recurrent somatic mutations in MAP2K1 and BRAF support a central role for ERK activation in $\mathrm{LCH}$ pathogenesis. Blood 2014;124:3007-3015.

8 Allen CE, Parsons DW. Biological and clinical significance of somatic mutations in Langerhans cell histiocytosis and related histiocytic neoplastic disorders. Hematology Am Soc Hematol Educ Program 2015;2015:559-564.

9 Haroche J, Abla O. Uncommon histiocytic disorders: Rosai-Dorfman, juvenile xanthogranuloma, and Erdheim-Chester disease. Hematology Am Soc Hematol Educ Program 2015;2015:571-578.

10 Tidyman WE, Rauen KA. The RASopathies: developmental syndromes of Ras/MAPK pathway dysregulation. Curr Opin Genet Dev 2009;19:230-236. 
11 Raygada M, Arthur DC, Wayne AS, et al. Juvenile xanthogranuloma in a child with previously unsuspected neurofibromatosis type 1 and juvenile myelomonocytic leukemia. Pediatr Blood Cancer 2010;54:173-175.

12 Stieglitz E, Taylor-Weiner AN, Chang TY, et al. The genomic landscape of juvenile myelomonocytic leukemia. Nat Genet 2015;47:1326-1333.

13 Diamond EL, Durham BH, Haroche J, et al. Diverse and targetable kinase alterations drive histiocytic neoplasms. Cancer Discov 2016;6:154-165.

14 Badalian-Very G, Vergilio JA, Degar BA, et al. Recurrent BRAF mutations in Langerhans cell histiocytosis. Blood 2010;116:1919-1923.

15 Berres ML, Lim KP, Peters $\mathrm{T}$, et al. BRAF-V600E expression in precursor versus differentiated dendritic cells defines clinically distinct LCH risk groups. J Exp Med 2014;211:669-683.

16 Haroche J, Charlotte F, Arnaud L, et al. High prevalence of BRAF V600E mutations in Erdheim-Chester disease but not in other non-Langerhans cell histiocytoses. Blood 2012;120:2700-2703.

17 Betts DR, Greiner J, Feldges A, et al. Constitutional balanced chromosomal rearrangements and neoplasm in children. J Pediatr Hematol Oncol 2001;23:582-584.

18 de Graaf JH, Timens W, Tamminga RY, et al. Deep juvenile xanthogranuloma: a lesion related to dermal indeterminate cells. Hum Pathol 1992;23: 905-910.

19 Freyer DR, Kennedy R, Bostrom BC, et al. Juvenile xanthogranuloma: forms of systemic disease and their clinical implications. J Pediatr 1996;129: 227-237.

20 Jans SR, Schomerus E, Bygum A. Neurofibromatosis type 1 diagnosed in a child based on multiple juvenile xanthogranulomas and juvenile myelomonocytic leukemia. Pediatr Dermatol 2015;32:e29-e32.

21 Shin HT, Harris MB, Orlow SJ. Juvenile myelomonocytic leukemia presenting with features of hemophagocytic lymphohistiocytosis in association with neurofibromatosis and juvenile xanthogranulomas. J Pediatr Hematol Oncol 2004;26:591-595.

22 Rowe LR, Thaker HM, Opitz JM, et al. Molecular inversion probe array for the genetic evaluation of stillbirth using formalin-fixed, paraffin-embedded tissue. J Mol Diagn 2013;15:466-472.

23 Wang Y, Cottman M, Schiffman JD. Molecular inversion probes: a novel microarray technology and its application in cancer research. Cancer Genet 2012;205: 341-355.

24 Wang Y, Carlton VE, Karlin-Neumann G, et al. High quality copy number and genotype data from FFPE samples using Molecular Inversion Probe (MIP) microarrays. BMC Med Genomics 2009;2:8.

25 Wang Y, Moorhead M, Karlin-Neumann G, et al. Analysis of molecular inversion probe performance for allele copy number determination. Genome Biol 2007;8:R246.

26 Caputo R, Zelger B. Juvenile xanthogranuloma. In: LeBoit PE, Burg G, Weedon D, Sarasin A (eds). WHO Classification of Tumours: Pathology and genetics of skin tumours. 3rd edn. IARC Press: Lyon, France, 2006, pp 222-223.

27 Paxton CN, Rowe LR, South ST. Streamlining the OncoScan(R) Array Procedure for Use in a Clinical Laboratory. J Assoc Genet Technol 2015;41:61-65.

28 Conlin LK, Thiel BD, Bonnemann CG, et al. Mechanisms of mosaicism, chimerism and uniparental disomy identified by single nucleotide polymorphism array analysis. Hum Mol Genet 2010;19:1263-1275. 